\title{
A Utilização do Livro Didático de Ciências na Prática Escolar
}

\author{
La Utilización del Libro Didáctico de Ciencias en la Práctica Escolar
}

The use of the Science Textbooks in School Practice

\author{
Taina Guerra Chimieski ${ }^{1}$ \\ Raquel Pereira Quadrado
}

\begin{abstract}
Resumo
O presente artigo busca analisar a relação estabelecida entre docentes e o livro didático. Para tal, foram realizadas quatro entrevistas semi-estruturadas com professores/as que lecionam no município do Rio Grande, RS. A estratégia de investigação narrativa foi utilizada para analisar as entrevistas. As falas dos/as docentes apontam um deslocamento na maneira de utilizar o livro didático, pois se anteriormente este servia de apoio para os estudantes hoje ele vem servindo de material de pesquisa para os/as professores/as, que buscam este subsídios para elaborarem seus planejamentos diários.
\end{abstract}

Palavras-chave: corpos; livro didático; ensino.

\section{Resumen}

El presente artículo busca analizar la relación establecida entre docentes y el libro didáctico. Para ello, se realizaron cuatro entrevistas semiestructuradas con profesores / as que enseñan en el municipio do Rio Grande, RS. La estrategia de investigación narrativa fue utilizada para analizar las entrevistas. Las palabras de los / las docentes apuntan un desplazamiento en la manera de utilizar el libro didáctico, pues si anteriormente éste servía de apoyo para los estudiantes hoy él viene sirviendo de material de investigación para los / las profesores I as, que buscan este subsidios para elaborar sus planificaciones diarias.

Palabras clave: cuerpos; libro didactico; enseñanza.

\section{Abstract}

This article seeks to analyze the relationship established between teachers and the textbook. For that, four semistructured interviews were conducted with teachers who teach in the city of Rio Grande, RS. The narrative research strategy was used to analyze the interviews. The teachers' speeches indicate a change in the way in which the textbook is used, because if it was previously used as a support for students, todays it has been used as a research material for teachers, who seek these subsidies to elaborate their daily planner.

Keywords: bodies; textbook; teaching.

\section{Considerações Iniciais}

Nas últimas décadas o currículo escolar tem estado no centro de discussões do campo da educação, que nos possibilitam problematizar seu papel e importância nas instituições escolares. Ao olharmos para o currículo é importante percebê-lo como uma construção social e histórica marcada por relações de poder. Assim, seu papel é muito maior do que compor a

\footnotetext{
1 Mestre em Educação; Universidade Federal do Rio Grande - FURG; Rio Grande, RS, Brasil; taina.bio@hotmail.com.

2 Doutora em Educação em Ciências: Química da vida e saúde; Universidade Federal do Rio Grande - FURG; Rio Grande, RS, Brasil; raquelquadrado@hotmail.com.
} 
grade curricular, ao legitimar determinados conhecimentos que devem fazer parte das práticas de ensino aprendizagem e excluir outros, ele produz visões particulares do mundo. Desta forma, entendemos que o currículo não é “[...] um meio neutro de transmissão de conhecimentos ou informações. [...] Ao determinar quem está autorizado a falar, quando, sobre o quê, quais conhecimentos são autorizados, legítimos, o currículo controla, regula, governa" (SILVA, 2013, p.196).

Ao analisarmos os currículos escolares atuais, é possível perceber que grande parte apresentam-se de forma fragmentada, descontextualizada, marcados por não representar a realidade dos estudantes, por abordar conteúdos isolados de seu contexto histórico, sóciocultural e político. Esta compartimentalização também pode ser observada nos livros didáticos, que assim como os currículos desconsideram a diversidade cultural e privilegiam visões hegemônicas da sociedade, tornando-se desinteressante para os/as estudantes por não estabelecer significado para os/as mesmos/as.

O livro didático é um dos representantes mais marcantes da cultura escolar. Este material facilmente encontrado em grande parte das salas de aula, é um recurso de fácil acesso aos professores e estudantes, principalmente por ser distribuído de forma gratuita pelos órgãos governamentais, através do Programa Nacional do Livro Didático (PNLD). Nos últimos anos muitas pesquisas, que tem como foco este material, passaram a ser realizadas como aponta Kazumi Munakata (2013), entre os anos de 2001 e 2011 foram produzidos cerca de 800 trabalhos sobre o livro didático. Apesar do número crescente de pesquisas sobre o tema, pesquisas que abordam a relação entre o/a professor/a e o livro didático ainda são pouco estudadas (GARCIA, 2009).

Neste estudo, lançamos nosso olhar para os livros didáticos de ciências. No Brasil, em 2017, de acordo com dados do PNLD (BRASIL, 2016) foram distribuídos mais de 10 milhões de livros de ciências, somente das séries finais do ensino fundamental. Tendo em vista que livros didáticos são utilizados em praticamente todas as escolas públicas de Ensino Fundamental e Médio no Brasil, bem como sua importância na definição dos conteúdos de ciências a serem desenvolvidos nos diversos níveis de ensino, faz-se necessário pesquisas que analisem de que forma estes livros têm sido utilizados no espaço escolar pelos docentes. Neste sentido destacamos a relevância deste estudo que teve como objetivo, analisar como o livro didático de ciências vêm sendo utilizado por docentes do município de Rio Grande, RS Brasil. 


\section{Caminhos Metodológicos}

Para a elaboração desta pesquisa realizamos quatro entrevistas semi-estruturadas com dois professores e duas professoras de ciências que trabalham em distintas escolas do município do Rio Grande, RS. Estas tiveram a duração média de 60 minutos cada, aconteceram nos locais escolhidos pelos entrevistados e entrevistadas e foram gravadas em áudio, adotando-se os devidos cuidados éticos. $\mathrm{Na}$ análise dos dados utilizamos a investigação narrativa na perspectiva dos autores Larrosa (1996), Connelly e Clandinin (1995).

Compreendemos que a entrevista está além do modelo instituído, onde o/a pesquisador/a pergunta e o/a participante responde. Entendemos esta estratégia a partir de Rosa Silveira (2007) como uma construção cultural e socialmente situada entre entrevistador/a entrevistado/a, assim, é nesta arena de significados que entrevistador/a e entrevistado/a produzem outras verdades, experiências, histórias, olhares. Assim podem ser descritas como:

[... eventos discursivos complexos, forjados não só pela dupla entrevistador/entrevistado, mas também pelas imagens, representações, expectativas que circulam- de parte a parte- no momento e situação de realização das mesmas e, posteriormente, de sua escuta e análise. (SILVEIRA, 2007, p. 118)

No campo teórico em que estamos inseridas, dos Estudos Culturais a partir do viés pós-estruturalista, ao analisar as narrativas produzidas é preciso considerar que não há nada "oculto" em suas falas que necessite ser revelado. Temos que nos deter no que foi dito, ficar no nível do discurso, sem esquecer que a interação entre entrevistado/a e entrevistador/a constitui-se em razão de relações de poder. Em relação a isto, Rosa Silveira salienta que, se por um lado nossa representação usual de entrevistas "[...] tenda a incluir um sujeito perguntando, 'querendo saber', questionando, e chegando, em certas ocasiões, a encurralar o entrevistado [...], o entrevistado também lança mão de numerosas estratégias de fuga, substituição e subversão dos tópicos propostos" (2007, p. 124).

Considerando tais entendimentos, na realização das entrevistas não buscamos encontrar respostas absolutas sobre o/a participante, ou algo escondido nas entrelinhas que pudesse revelar "a verdade" sobre os fatos. Entendemos a entrevista "[...] como a instância central que, somada às outras, traz informações fundamentais acerca do vivido e possibilita uma interpretação (mesmo que provisória e parcial)” (ANDRADE, 2012, p. 175).

Os dados das entrevistas foram tomados como dados narrativos. A narrativa pode ser entendida como uma prática social que está imbricada na produção dos sujeitos, visto que no 
contar e ouvir de histórias vamos produzindo nossa história. A partir de Larrosa (1996) entendemos que a história de nossas vidas é constituída por muitas histórias, "nossa história é sempre uma história polifônica" (1996, p. 465). Assim, é no gigantesco e agitado encontro de narrativas que vamos nos inventando, nos produzindo, nos modificando, construindo a nossa subjetividade. Desta maneira durante as entrevistas, os docentes ao narrarem também foram produzindo e dando visibilidade as suas próprias histórias.

Tendo em mente tais questões, analisamos as entrevistas dos professores sobre como eles vêm utilizando o livro didático de ciências em suas práticas docentes. Após algumas leituras das narrativas, passamos a agrupar por semelhança falas que estabeleciam relações umas com as outras. Ao final desse processo, relemos as entrevistas e as reagrupamos em dois eixos temáticos. Tais eixos são problematizados a seguir.

\section{Resultados}

Neste primeiro eixo apresentamos as narrativas dos docentes acerca da maneira de como eles vêm utilizando o livro didático de ciências em suas práticas. Ao serem indagados sobre como como têm utilizado o livro didático de ciências, os professores responderam:

Daniel $^{3}$ - [...] não era tão usado, era bem de vez em quando, tipo, quanto de alguma dúvida um ou dois alunos iam lá pegar, estudar, dar uma pesquisada.

Clarice - Ás vezes eu uso o livro didático mas como um suporte pra mim, pra preparar o material, algo que eu vá levar para eles, eu uso a internet, e o livro didático dificilmente mesmo eu uso em sala de aula é muito raro, olha esse ano eu acho que eu nem usei.

Alice - Então, tenho vários livros. Geralmente quando eu vou planejar a minha aula eu gosto de olhar os livros, até pra saber o aprofundamento que vem trazendo pro ensino de ciências para aquela série, também para não aprofundar demais ou de menos, sempre procuro dar uma olhada no livro didático.

As narrativas apresentadas, apontam que o livro didático de ciências têm sido utilizado pelos docentes de distintas maneiras. Podemos destacar que este material tem auxiliado os professores no planejamento de suas aulas, servindo tanto de fonte de pesquisa para os temas abordados como também norteando o nível de aprofundamento das discussões do conteúdo. Além disso, ainda é utilizado para sanar as dúvidas dos estudantes na sala de aula.

\footnotetext{
${ }^{3}$ Os nomes apresentados aqui são pseudônimos, escolhidos pelos participantes a fim de manter o anonimato.
} 
Esta forma de utilização do livro didático também foi observada por Jorge Neto e Hilário Fracalanza. Na pesquisa realizada em 2003, tais autores apontam que:

\begin{abstract}
Os usos que os professores alegam fazer do livro didático em suas atividades docentes foram aglutinados em três grandes grupos. Num primeiro grupo, os professores indicam uso simultâneo de várias coleções didáticas, de editoras ou autores distintos, para elaborar o planejamento anual de suas aulas e para a preparação das mesmas ao longo do período letivo. Num segundo grupo, comentam que o livro didático é utilizado como apoio às atividades de ensino-aprendizagem, seja no magistério em sala de aula, seja em atividades extra-escolares, visando especialmente a leitura de textos, a realização de exercícios e de outras atividades ou, ainda, como fonte de imagens para os estudos escolares, aproveitando fotos, desenhos, mapas e gráficos existentes nos livros. Por fim, num terceiro grupo, os professores salientam que o livro didático é utilizado como fonte bibliográfica, tanto para complementar seus próprios conhecimentos, quanto para a aprendizagem dos alunos, em especial na realização das chamadas "pesquisas" bibliográficas escolares. (2003, p.148)
\end{abstract}

As falas dos docentes apontam que o livro didático de ciências muitas vezes é utilizado por eles para determinar a sequência dos conteúdos a serem trabalhados e o grau de aprofundamento que este deve ter em cada série de ensino. Este uso do livro didático como "instrumento principal que orienta os conteúdos que devem ser desenvolvidos, a sequência desses conteúdos, as atividades de aprendizagem e a avaliação para o ensino", também foi observado por Frison, Vianna, Chaves e Bernardi (2009) em pesquisa realizada com docentes de ciências.

As narrativas expostas indicam ainda que quando este material é utilizado pelos estudantes em sala de aula é no intuito de tirar alguma dúvida ou realizar pesquisas. Em relação a esta prática, consideramos que embora outros recursos possam ser utilizados para a pesquisa, como por exemplo a internet, "o livro didático ainda representa a principal, senão a única fonte de trabalho como material impresso na sala de aula, em muitas escolas da rede pública de ensino" (FRISON et. al. 2009).

Os professores que destacaram o uso do livro didático de ciências como fonte de pesquisa em sala de aula, justificaram esse uso a partir de dificuldades apresentadas pela infraestrutura da rede de internet, que se mostra deficiente em suas escolas, conforme podemos ver nos excertos abaixo:

Clarice - [...] a gente ainda não têm acesso à internet porque como é zona rural ainda não tem lá.

Alice - [...] eu usava o livro para eles pesquisarem, porque a internet nem sempre funciona, nem sempre tu tem acesso, ou as outras turmas estão usando, é bem complicado a internet na escola, ou se começa a 
usar e aí para tudo, não têm tantos computadores assim, aí tem que fazer grupos.

Embora grande parte das escolas municipais e estudais da cidade do Rio Grande, RS possuam laboratórios de informática, estes espaços nem sempre são utilizados. Entre os motivos que inviabilizam sua utilização, apontamos o espaço físico, que por vezes não comporta mais do que vinte estudantes, os computadores obsoletos ou na maioria das vezes estragados e a falta de uma conexão de internet de qualidade, que suporte as demandas das instituições escolares. Sorj e Lissovsky (2011, p.22), destacam que "em apenas metade dos laboratórios, todos os computadores disponíveis funcionam com regularidade $(51 \%)$; em outros 30\%, mais da metade dos equipamentos funciona regularmente; em 19\%, nenhum ou menos da metade dos computadores funcionam adequadamente.

Desta forma, entendemos que devido as limitações apresentadas na utilização da internet como fonte de pesquisa no ambiente escolar, o livro didático exerce esta função. No segundo eixo analisamos os motivos que contribuíram para que o livro didático de ciências não fosse utilizado de forma regular pelos docentes em suas práticas.

Clarice - [...] a nossa escola não recebe muitos livros, porque é anexo de uma escola da cidade, então às vezes vai [livros didáticos de ciências] e às vezes o que vai também não é muito bom. [...] às vezes eu acho ele distante do que eu quero para aquela aula, não é bem aquele objetivo que eu quero, então eu acho meio complicado.

Morpheu - [...] o livro didático às vezes é muito limitado para algumas coisas, para você ver, agora eu tô com um livro didático, mas é de 2002 os livros mais antigos, não sei, eles traziam os conteúdos de uma maneira mais prática. [...] E agora os livros didáticos trazem menos questões e muito texto.

Alice - É difícil pegar um livro que seja bom em todos os anos e em todos os conteúdos, então quando tu tem vários, tu consegue ir usando alguma coisa, não que tu vai seguir o livro[...]. Não tem livro para todo mundo, então tu não pode seguir o livro para conteúdo porque não tem para todo mundo, se eles quiserem tem que ir na biblioteca.

Nas narrativas apresentadas acima podemos perceber que o número insuficiente de livros didáticos para todos os estudantes, a distância entre o que o professor objetiva para sua aula e o que o livro propõe, poucos exercícios e o fato de uma coleção de livro didáticos não ser considerada satisfatória para todos os graus de ensino são alguns dos motivos apontados 
pelos professores que limitam a utilização regular do livro didático de ciências em sala de aula.

Os livros didáticos são distribuídos a cada triênio nas escolas, a partir do Programa Nacional do Livro Didático. Assim, a cada final de ano letivo os estudantes devem devolver os livros para a escola, a fim de serem utilizados novamente no ano seguinte, pelas novas turmas. Entretanto, as falas indicam que nem sempre tal prática ocorre, ocasionando uma demanda maior por livros do que a disponibilidade existente. Outro fator limitante para a utilização do material é o fato de que durante a escolha dos livros os docentes têm de escolher uma coleção única para todos os anos, o que pode ocasionar que um livro seja muito bom no sétimo ano, mas insatisfatório no nono ano, por exemplo.

\section{Conclusões}

O livro didático, ainda hoje em meio a tantas tecnologias, continua sendo muito utilizados pelos docentes. Embora outros materiais venham sendo utilizados para subsidiar e auxiliar os docentes em suas práticas, é ao livro didático que eles recorrem para planejar, definir quais conteúdos devem ser trabalhados em cada série e qual o nível de aprofundamento.

$\mathrm{Na}$ sala de aula este material não é trabalhado de forma regular tendo em vista, que o número de exemplares disponíveis nem sempre está de acordo com a quantidade de estudantes. Além disso, a distância existente entre o que o docente objetiva para sua aula e o que o livro propõe, e a existência de poucos exercícios sobre os conteúdos abordados, também limitam a utilização deste. Assim, para os participantes desta pesquisa o livro didático tem sido utilizado como fonte de pesquisa, tanto para os estudantes, auxiliando nos trabalhos escolares, quanto para os docentes, contribuindo no planejamento curricular de suas aulas.

\section{Referências}

ANDRADE, Sandra dos Santos. A entrevista narrativa ressignificada nas pesquisas educacionais pós-estruturalista. In: MEYER, Dagmar E; PARAISO, Marlucy A. (Orgs.) Metodologias de pesquisa pós-críticas em educação. Belo Horizonte: Mazza, 2012.

BRASIL. Ministério da Educação. Fundo Nacional de Desenvolvimento da Educação FNDE. Programas. Livro Didático - PNLD. Disponível em <http://www.fnde.gov.br/programas/livro-didatico>. Acesso em: 16 nov. 2016.

CONNELLY, M.; CLANDININ, J. Relatos de experiencia e investigación narrativa. In: LARROSA, J. et al. Déjame que te cuente: ensayos sobre narrativa y educación. ed. Barcelona: Laertes, 1995. p.11-59. 
FRISON, M. D.; VIANNA, J.; CHAVES, J. M.; BERNARDI, F. N. Livro didático como instrumento de apoio para construção de propostas de ensino de ciências naturais. In: Encontro Nacional de Pesquisa em Educação em Ciências, 2009. Florianópolis, SC.

GARCIA, T. M. F. B. Relações de professores e alunos com os livros didáticos de Física. In: XVIII simpósio Nacional de Ensino de Física, 2009, Vitória, ES. XVIII Simpósio Nacional de Ensino de Física Formação Continuada de Professores em Serviço: Educação de Qualidade para uma Sociedade da Aprendizagem. Vitória: SBF, 2009, p. 1-10.

LARROSA, J. Narrativa, identidad y desidentificación. In: LARROSA, J. La experiencia de la lectura. Barcelona: Laertes, 1996. p. 461-482.

MUNAKATA, Kazumi. O livro didático: alguns temas de pesquisa. Rev. bras. hist. educ., Campinas-SP, v. 12, n. 3 (30), p. 179-197, set./dez. 2012.

NETO, J. M.; FRACALANZA, H. O Livro Didático de Ciências: problemas e soluções. Ciência \& Educação. 2003. v. 9, n. 2, p. 147-157.

SILVA, Tomaz Tadeu da. Currículo e identidade social: territórios contestados. In:__. (Org). Alienígenas na sala de aula - uma introdução aos estudos culturais em educação. 11. ed. Petrópolis: Vozes, 2013, p. 185 - 202.

SILVEIRA, R. M. H. A entrevista na pesquisa em educação - uma arena de significados. In: COSTA, M. V. (Org.). Caminhos Investigativos II: outros modos de pensar e fazer pesquisa em educação. 2. ed. Rio de Janeiro: Lamparina, 2007.p.117-138.

SORJ, B.; LISSOVSKY, M. Internet nas escolas públicas: política além da política. Centro Edelstein de Pesquisas Sociais. Rio de Janeiro. Working Paper n 6. 2011. 